\title{
Donnerstag, den 12. Oktober 2017, 17.45 Uhr, 41. Dreiländertreffen in Linz, Design Center Linz, Raum Seminar 2
}

Sehr geehrte Kolleginnen, sehr geehrte Kollegen, liebe Mitglieder der DEGUM,

im Namen des Vorstandes lade ich Sie hiermit herzlich zur Mitgliederversammlung der DEGUM am Donnerstag, den 12.10.2017, 17.45 Uhr im Design Center Linz, Raum Seminar 2, ein.

Gleichzeitig möchte ich Sie auch zum diesjährigen Dreiländertreffen einladen, welches vom 11. bis 13.10.2017 in Linz stattfindet.

Wolfgang Arzt als Kongreßpräsident und seine Mitarbeiter haben in Zusammenarbeit mit der Fortbildungskommission von DEGUM, ÖGUM und SGUM ein Programm zusammengestellt, dass die Interessen aller in der DEGUM vertretenen Fachgruppen und die aktuellen Entwicklungen im Ultraschall berücksichtigt. Neben dem fachlichen Austausch können Sie sich auch in diesem Jahr wieder über die neuesten Entwicklungen der Industrie informieren.

Bitte nutzen Sie diese einzigartige Möglichkeit zur fachlichen Weiterbildung und zum persönlichen Austausch mit Kollegen und Freunden rund um das Thema „Ultraschall“.

Ich würde mich freuen, Sie im Oktober in Linz begrüßen zu können.

PD Dr. Kai - Sven Heling, Präsident
Tagesordnung

- TOP 1: Annahme der Tagesordnung

- TOP 2: Annahme des Protokolls der Mitgliederversammlung am 28.10.2016 bei dem 40. Dreiländertreffen in Leipzig

- TOP 3: Bericht des Vorstandes

- TOP 4: Bericht des Schatzmeisters

- TOP 5: Entlastung des Vorstandes

- TOP 6: Aufnahme neuer Mitglieder

- TOP 7: Ehrungen

- Preise (Wissenschaft und Promotion)

- Ehrenmitgliedschaften

- TOP 8: Berichte aus den Sektionen und Arbeitskreisen

- TOP 9: Verschiedenes

PD Dr. med. K.-S. Heling, Präsident Prof. Dr. med. A. Hagendorff, Sekretär 